DEL DESCONTROL DE LA REVUELTA AL CONTROL DE LA PANDEMIA

\author{
Nelly Richard
}




\section{NELLY RICHARD}

Crítica cultural y ensayista. Fue fundadora y directora de la Revista de Crítica Cultural entre 1990 y 2008. Recibió la Beca Guggenheim en 1996. Es autora de Crítica y política (2013), Feminismo, género y diferencia(s) (2008); y Residuos y metáforas. Ensayos de crítica cultural sobre el Chile de la transición (1998), entre otros libros. 


\section{DEL DESCONTROL DE LA REVUELTA AL CONTROL DE LA PANDEMIA}

\section{EL COLAPSO DE LOS TIEMPOS VITALES: DEL ENTUSIASMO DEL RENACER (“CHILE DESPERTÓ”) A LA DESACTIVACIÓN DEL FUTURO}

En su expansión mundial, la epidemia del Coronavirus llegó a Chile en pleno trance de revuelta social: una revuelta con carácter de insurrección que, iniciada el 18 de octubre de 2019, levantó la consigna "Chile despertó" para dejar claro que una sociedad mayoritariamente silenciada por su exceso de conformismo transicional había perdido el miedo a manifestar su vibrante rechazo al régimen de desigualdades, abusos y privilegios administrado por la dominación neoliberal. Multitudes se adueñaron del espacio público para decirle "ya basta" al poder instituido y abrir nuevos horizontes de lo posible. Si bien los contenidos de las demandas ciudadanas referidas a educación, salud, trabajo, pensiones, etc., no estaban programáticamente articulados en una agenda de cambios muy definida, todas estas demandas comenzaron a girar en torno al "significante flotante" de la asamblea constituyente como ruptura manifiesta con la herencia de la Constitución de Augusto Pinochet que, impuesta al país en 1980, consagró el desmantelamiento del Estado a favor de la triunfal consolidación del mercado.

Es cierto que se generaron discusiones varias en el interior de la(s) izquierda(s) sobre si había que resignarse o no a aceptar los condicionamientos políticos que enmarcaron el llamado al plebiscito nacional que se vio obligado a anunciar el gobierno de Sebastián Piñera (15 de noviembre, 2019) para ratificar el acuerdo parlamentario recientemente firmado: un acuerdo que, por lo demás, fue puesto inmediatamente bajo sospecha debido al elitismo de su pacto, que excluía a las organizaciones sociales. Es también cierto que se abrieron extensos debates en la(s) izquierda(s) sobre cómo presionar desde la sociedad civil para vencer estos condicionamientos político-institucionales demasiado restrictivos y lograr una reformulación más ampliamente participativa de las bases y mecanismos del

1. Empleo el término "significante flotante" según la interpretación que le ha dado el teórico Ernesto Laclau en varios de sus libros: el de una figura discursiva que fija los significados dispersos de la cadena de significaciones, reduciendo parcialmente su ambigüedad y polisemia. 
itinerario constituyente. Pero, en cualquier caso, para quienes comparten el "ya basta" de la revuelta de octubre de 2019, la asamblea constituyente señala algo refundacional: la apertura de un tiempo de deliberación colectiva sobre el futuro de la democracia a cargo de una ciudadanía que recupera su protagonismo políticosocial después de que este se hubiese visto confiscado durante los largos años de la transición por los formalismos y tecnicismos del consenso neoliberal. El tiempo inaugural detonado por la revuelta de octubre de 2019 (un tiempo de promesas que convoca lo que está por-venir) se vivió como un tiempo energético: un tiempo intensivo, acelerado y casi frenético en sus ritmos de destitución de lo viejo y de invención de lo nuevo. Aquel tiempo transcurrido entre octubre y marzo, un tiempo de aceleración y precipitación, de sobreexcitación de los deseos de futuro, se vio bruscamente cortado en sus ritmos vitales por la epidemia y sus cuarentenas.

Quizás lo más sensible de lo ocurrido en Chile haya sido este colapso del tiempo/ de los tiempos que nos llevó tan súbitamente de la movilización de los deseos colectivos (octubre de 2019) a la inmovilización forzada y a la reclusión individual (marzo de 2020). La pandemia nos arrebató el tiempo excepcional de la revuelta social (lo excepcional como lo fuera-de-serie) para condenarnos al tiempo ordinario de la cuarentena y su monótona repetición de lo mismo. Dice Alejandra Castillo:

El tiempo de la cuarentena es (...) un tiempo que marca el inicio y el término de una reclusión. El tiempo de la cuarentena es, por ello, un afuera del tiempo. $\mathrm{O}$, dicho de otro modo, la cuarentena activada por mandato gubernamental es una unidad de tiempo sin temporalidad. No hay proyecto que realizar en ella, solo pequeñas tareas repetitivas (...) que parecen acortar el tiempo - el futuro- al paso de los días, de las horas ${ }^{2}$.

Pasamos dramáticamente de la expectación despertada por un futuro a construir entre todos a la resignación de cada uno frente al tiempo detenido y recluido que paraliza todo movimiento hacia adelante: del tiempo hiper-activo (deseante, voluntarioso) de la insubordinación política al tiempo pasivo (resignado, estacionario) de la puesta en cuarentena. Si re-vivir (despertar del mal sueño de la abusiva oferta neoliberal) fue la consigna multitudinaria de octubre de 2019, varios son los que se preguntan hoy cómo sobrevivir, es decir, cómo retornar a mínimas condiciones de vida que amenazan con ser aún más deplorables que antes.

2. Alejandra Castillo, "Naufragio en el espectáculo de la catástrofe", Antígona feminista, 3 de abril, 2020 . 
Bien sabemos que lo socialmente aceptado como "normalidad" no responde a un orden natural, sino que es el producto de un sistema de códigos amarrado por la ideología de un determinado sentido común (económico, político, social) que termina por "normalizar" su existencia, volviendo automáticamente reproducibles sus fundamentos. La revuelta social de octubre de 2019 hizo explotar lo que el guion del neoliberalismo había naturalizado como ordenamiento político-económico y social, dejando en claro que la realidad vivida bajo el lema exitista del Chile próspero no era sino el efecto de significación dominante creado por el discurso hegemónico del híper-capitalismo. El estallido de octubre de 2019 evidenció las reglas privatizadoras y mercantilizadoras que los guardianes empresariales de aquel orden postulaban como inmodificables, demostrando que sí es posible dar vuelta el statu quo armando "re-vueltas". Deberemos preocuparnos de guardar viva la memoria de este aprendizaje emancipador sacado de octubre de 2019: no dejar fallecer el recuerdo de haber comprendido que los códigos económicos y sociales del modelo neoliberal pueden ser interrumpidos y desafiados por una imaginación política que se atreve a anticipar formas alternativas de habitar el mundo. Es decisivo retener (tener guardada) esta memoria de rebeldías e insumisiones antes de que se instale la "nueva normalidad" que anuncia complacidamente la derecha para borrar de un plumazo la toma de conciencia colectiva que le hizo saber al país que no existe normalidad cuya ficción no se deje resquebrajar por las latencias y sobresaltos de la crisis.

No cabe duda de que la dureza de las condiciones de vida que afloran como realidad cotidiana en estos tiempos de epidemia no hace sino revalidar los motivos que tuvo la revuelta de octubre de 2019 para sublevarse contra un régimen de desigualdades económicas y sociales que precariza y segrega pero, sobre todo, maltrata y ofende. Estos maltratos y ofensas se notan en las imágenes que desfilan a diario por nuestras pantallas de televisión: en el deterioro de los hospitales y del aparato de salud pública, en las desoladoras colas para cobrar seguros de cesantía después de masivos e injustificados despidos, en las inhóspitas condiciones de la vivienda social, en la descomposición de las periferias urbanas, en el indecente trato hacia los migrantes, en la acrecentada violencia sexual que acosa a las mujeres dentro de los hogares en cuarentena, etc. Esta catastrófica suma de desastres vinculados a la desprotección social que saltan a la vista con la pandemia no hace sino reconfirmar la legitimidad moral del "ya basta" (de abusos y privilegios) expresado por la revuelta de octubre de 2019 frente al saqueo capitalista. Pero, ¿basta esta suma de justificaciones que nos llevan a impugnar tanto el ordenamiento neoliberal del sistema capitalista como la razón gubernamental que sostiene la alianza de derecha de Sebastián Piñera, mediante fraudes y usurpaciones, para confiar en que 
el intervalo llamado "cuarentena" dejará intactas las ganas y fuerzas con las que multitudes saldrán nuevamente a las calles?

Una respuesta optimista a esta pregunta sacaría ventaja de cómo la explosión de las fuerzas sociales (incluyendo, por supuesto, a las fuerzas puestas en marcha por las organizaciones de mujeres) surgida en octubre de 2019 conforma un archivo vitalista de emociones colectivas que nos dotó de estímulos suficientes para superar este contratiempo y seguir tejiendo rebeldías ${ }^{3}$. Pero si bien esta convicción nos puede ayudar a no sucumbir en la apatía, devolviéndonos confianza en el futuro, quizás su optimismo deba ser matizado por la sospecha de que el "shock psicótico-viral"4 de la pandemia trae repercusiones de distintas escalas - macrofísicas y microfísicasque no son fáciles de amortiguar: desde los miedos primarios (a la enfermedad y la muerte) que asedian los cuerpos en desamparo hasta la perplejidad de la conciencia frente a la obligación de lidiar con un mapa del presente-futuro demasiado confuso, pasando por el decaimiento del ánimo y sus repliegues ensimismados. Franco "Bifo" Berardi reagrupa bajo el término de "psicodeflación" los distintos síntomas que revelan cómo la pandemia hizo que la energía se fuera retirando del cuerpo social: "cansada de procesar señales demasiado complejas, deprimida después de la excesiva sobreexcitación, humillada por la impotencia de sus decisiones frente a la omnipotencia del autómata tecno-financiero, la mente ha disminuido la tensión. No es que la mente haya decidido algo; es la caída repentina de la tensión la que decide por esta"'.

Este debilitamiento de la tensión física y mental que afecta el ánimo, los deseos y la voluntad, deja trazas en el organismo social y político que demoran en absorberse, sin contar los nuevos peligros que ya asoman en el camino trazado hacia su supuesta recuperación: el recrudecimiento neofascista de brotes totalitarios provenientes

3. Así lo afirman Javiera Manzi y Alondra Carrillo: "Lo cierto es que aunque a ratos no parezca de ese modo, este no es un paréntesis. Las paredes de nuestro hogar o los tránsitos temerosos en los transportes públicos de una ciudad reducida al mínimo de su actividad no son la señal de una pausa en el tiempo. No todo se ha detenido. (...) El proceso en el que nos encontrábamos subsiste subterráneamente en nuestras rabias, anhelos y preguntas; en nuestras redes y conspiraciones silenciosas (...). Puesto que esto no es un paréntesis sino que el tiempo sigue, la vida y la política también, la pregunta hoy no es qué haremos después de que esto pase (...). Lo que hagamos hoy será determinante para los escenarios de alternativa a la crisis, pero lo que ya veníamos haciendo es igualmente clave. No partimos desde cero en la revuelta y mucho menos partimos desde cero ahora. Hemos levantado un programa (un Plan de Emergencia Feminista) para transformar radicalmente el modo en que se organiza la vida, la vida toda". Javiera Manzi - Alondra Carrillo, voceras Coordinadora Feminista 8M, "La continuidad de nuestra revuelta a un mes del 8M", Lobo suelto, 8 de abril, 2020.

4. La expresión es de Franco "Bifo" Berardi, "Crónica de la psicodeflación", Sopa de Wuban. Pensamiento contemporáneo en tiempos de pandemias. Editorial Aspo, marzo, 2020.

5. Op. cit., p. 43. Los subrayados son de la autora. 
de ultraderechas que les ofrecen a las poblaciones inseguras promover el control represivo de las fronteras de los países y, también, enfrentarnos unos a otros, estimulando la sospecha, la denuncia y la hostilidad entre vecinos. Lo inhospitalario de un mundo sin resguardos y la fragilidad de los cuerpos asustados hacen que, frente a la adversidad, se consoliden tendencias reactivas-conservadoras en sectores de la población cuya búsqueda de seguridad los aleja del fantasma convulso de la rebelión social. Esta incierta lucha entre las fuerzas de desapropiación y de reapropiación de la vida que se libran en medio de la pandemia deja en suspenso saber cuándo y cómo podrá volver a abrirse curso alguna pulsación de lo nuevo decididamente orientada hacia un futuro transformador. El espíritu de la revuelta ha sido tocado por la epidemia en la medida en que es la sensorialidad misma de nuestro aparato perceptivo y cognitivo de la experiencia social la que "mutó" en sus afecciones (en el doble sentido de querer algo y/o dejarse modificar por un efecto que trae consecuencias sensibles), y no reconocerlo peca de voluntarismo cuando es la voluntad misma la que se quiebra o bien, oscila.

\section{LA "DES-INFECCIÓN" DE LAS MARCAS CONTAMINANTES DE LA REVUELTA SOCIAL EN LA CIUDAD Y EL DISCURSO PÚBLICO}

La revuelta social de octubre de 2019 significó que multitudes reconquistaran lo público (calles y plazas) para compartir la experiencia de un estar-juntos en el reclamo y la protesta contra los modos de hacer del sistema neoliberal. Recuperar el uso público de los espacios movilizando grupos y sujetos reforzó el sentido de colectividad y asociatividad cuyos vínculos había roto la privatización neoliberal. El aislamiento forzado de la cuarentena que desalojó a la población de las calles privó a las subjetividades de la revuelta de una exterioridad pública hacia la cual volcar las energías. A la vez, las nuevas consignas impuestas por el libreto oficial en torno a la pandemia modificaron las prioridades del discurso público. A la privación causada por la falta de multitudes que llenaban las calles se suma la incomodidad de tener que asistir a cómo la agenda político-nacional le torció el rumbo al camino elegido por el malestar para expresarse vehementemente. La revuelta de octubre de 2019 había tenido como enemigo declarado al gobierno de Sebastián Piñera, al que logró hacer caer en un precipicio de deslegitimación. Sin embargo, el vuelco de la pandemia le dio oportunidad y pretexto a este mismo gobierno para retornar a escena, queriendo demostrar ahora operatividad y eficiencia (dos de los vocablos predilectos de la gestión tecnocrática) en el control de la contingencia sanitaria centralizado en el Ministerio de Salud sin dejar, por supuesto, de cuidar a los mercados que resguardan los intereses privados de las empresas. 
La obsesiva y paranoica cobertura mediática de la epidemia de Coronavirus en la televisión (curvas estadísticas, porcentajes demográficos, informes científicos, recomendaciones médicas, manuales de higiene y cuidado, etc.) hizo desaparecer de las pantallas las imágenes que, desde octubre de 2019, las habían invadido: las de la ciudad alborotada y su población insurrecta. Los medios se apresuraron en operar un completo barrido de todas las imágenes de la revuelta, queriendo relegar sus espasmos al tiempo arcaico de una fiebre político-social que debe ser aplacada en un contexto de urgencia sanitaria. Además, el gobierno de Sebastián Piñera aprovechó el control policial en las calles para "limpiar" a la ciudad de las muestras gráficas que testimonian el alzamiento popular, reintroduciendo señales normalizadoras (la reposición de los semáforos, la pintura de muros y edificios, la rehabilitación de las estaciones de metro destruidas, etc.) que dejarían en el olvido la virulencia contestataria desatada contra el paisajismo arquitectónico de lo comercial que ambienta la ciudad en su versión modernizadora. La epidemia sirvió en Chile de pretexto higienista y sanitizador para "des-infectar" a la ciudad de la suciedad y turbiedad de las huellas de la insubordinación social que "manchan" las estéticas publicitarias del consumo, sus marcas y logotipos, con las sombras disfuncionales de una rabia inorgánica.

En medio de este operativo general de limpieza y desinfección del entorno urbano, Sebastián Piñera llegó al colmo de la provocación realizando una excursión a la Plaza de la Dignidad (ex Plaza Italia), donde se hizo retratar en una pose en la que finge "dominar" la escena, solo que su prepotencia se exhibe frente a una plaza desierta y una ciudad vacía. La pose desafiante del mandatario ocupa el vaciamiento de la ciudad como escenografía trucada para simular que volvió a ejercer el dominio del poder. Patetismo e insolencia de una ritualidad del mando que ya nos ha acostumbrado a su comedia de equivocaciones:

Su performance de conquistador (la de Piñera) hace el ridículo desde el momento en que con su curiosa sentada mirando hacia donde se pone el sol (es decir, ¿contemplando su propio crepúsculo?) no conquista a ningún "enemigo poderoso", ni siquiera a algún "enemigo" a secas... Tan solo un miserable turista sacándose fotos en una ruina abandonada ${ }^{6}$.

La epidemia le sirvió también de excusa al gobierno de Sebastián Piñera para decretar un Estado de Excepción con toque de queda (18 de marzo de 2020),

6. Rodrigo Karmy, "El pastor y el estúpido; sobre el devenir cómico de una teología política”, El Mostrador, 6 de abril, 2020. 
lo que justificó la salida de los militares a la calle: los mismos militares y policías cuyos uniformes llevan estampado el recuerdo siniestro de la persecución militar en dictadura y que se vieron nuevamente envueltos en abusos consignados como violaciones de los derechos humanos por los informes internacionales al actuar con violencia represiva contra los manifestantes de la protesta de octubre de 2019. Sin embargo, son estas mismas fuerzas militares y policiales las que hoy vigilan el cumplimiento de las medidas sanitarias y fiscalizan los salvoconductos que autorizan a transitar por la ciudad. Esta chocante paradoja de los uniformes militares en conversión de roles debido a la pandemia trae costos emocionales al desarmar nuestra memoria histórica del combate y la resistencia. La cara visible de las ciudades de hoy en Chile, con los militares incluidos en las tareas prácticas de organización del cotidiano, parecería sugerir - al menos en superficie-que pasamos de la desobediencia (evadir, rechazar, enfrentar, combatir) a la obediencia forzada (acatar órdenes, pedir permiso, dejarse controlar y sancionar), lo que genera una grieta perturbadora en el imaginario de la insumisión que se había expandido masivamente desde octubre de 2019. Pero no solo el paisaje urbano se ha visto reconfigurado por el vaciamiento de la ciudad y el control policial de la población. La esfera del discurso público ha experimentado sorprendentes virajes semánticos: la expresión "primera línea" (zona del enfrentamiento cuerpo a cuerpo de los escuderos contra las fuerzas policiales durante las protestas, que fue glorificada con una mística combatiente) se usa hoy para designar la lucha del personal de la salud que cuida enfermos y salva vidas, como si los cuerpos se hubiesen desplazado del registro heroico de la lucha temeraria contra policías y militares (octubre de 2019) al registro fragilizado de lo temeroso frente al virus (marzo de 2020). Del descontrol de la revuelta al control de la epidemia: el cambio de tablero ha sido tan brusco en materia de paisajes, signos y corporalidades (del emblema guerrillero de la capucha a la seguridad protectora de la mascarilla; de la vestimenta negra del tumulto anarquista a la blancura asistencial de los delantales médicos) que cabe preguntarse cómo se reordenarán los repertorios simbólicos de la frustración.

\section{EL FEMINISMO COMO ARCHIVO DE SABERES Y EXPERIENCIAS}

La pandemia del Coronavirus no solo introduce el miedo en los universos familiares del cotidiano ni hace naufragar las economías mundiales. También nos ha llenado de desconcierto ver todas las ciudades del planeta deshabitadas por el confinamiento y transformadas en el set de algún cine postapocalíptico o bien asistir a cómo los aparatos productivos y los sistemas comerciales cayeron en una fase global de inacción forzada, cumpliendo, irónicamente, el sueño anticapitalista de una "huelga 
general" capaz de paralizar la fuerza mundial de trabajo. La extrañeza de este mundo distópico que dibuja la pandemia no puede sino generar perturbación y confusión en los marcos de explicación y comprensión del mundo, en los sistemas de referencia y lectura de cómo evoluciona el mundo. La pérdida de certezas a la que nos enfrenta la pandemia y el extravío de los horizontes de futuro que se encuentran hoy desalineados en el planeta nos indican que solo nos queda asumir la falibilidad de cualquier marco de análisis. Sin embargo, no todos aceptan esta falibilidad del juicio producto del desbarajuste de las hipótesis de interpretación general. Son varios los filósofos e intelectuales contemporáneos que, apenas declarada la pandemia, intervinieron en el debate internacional para meditar sobre el futuro de la globalización capitalista ${ }^{7}$. Algunos de ellos aprovecharon de confirmar que el miedo al contagio le servirá al capitalismo para cumplir sus designios biopolíticos, que consisten en extremar el control social sobre los cuerpos mediante nuevas formas de disciplinamiento de las poblaciones que incluyen hasta lo tecno-militar. Otros anuncian, por el contrario, que el gigantesco descalabro económico provocado por la pandemia en las cadenas de funcionamiento de los mercados y las finanzas va a significar un golpe tan fatal para la expansión capitalista que obligará a sus tendencias monopólicas a ceder frente al inevitable surgimiento de nuevas formas de cooperación entre Estados, organismos y comunidades que les cambiarán el rostro a las democracias corporativas. No hay sistema de predicción que valga frente a la incertidumbre de este tiempo en suspenso, al que le cuesta reponerse de la conmoción. Pueden ser igualmente válidas las distintas e incluso opuestas hipótesis que se manejan frente a lo que viene (la exacerbación del capitalismo o bien su progresiva desestructuración), aunque lo más seguro es que, como siempre, los cambios a efectuarse no partan de un corte nítido - sin remanentes- del futuro con el pasado, sino que ocupen distintas fases transicionales que mezclan rasgos híbridos en combinaciones intermedias.

Cualesquiera sean las alternativas, lo que sí debería aparecer como evidencia es que ningún pensamiento sobre/de la crisis del capitalismo global puede hoy prescindir del feminismo como clave de análisis y como apuesta de futuro. En efecto, el feminismo ha subrayado con absoluta lucidez varios de los motivos que se entrecruzan en el balance de esta crisis, descifrando, desde la perspectiva de género, la "feminización de la pobreza" que ocupa a las mujeres como nuevas zonas de sacrificio; la oposición entre lo privado y lo público como base material para la hipervaloración de lo

7. Las principales intervenciones de intelectuales globales han sido recogidas en Sopa de Wuhan. Pensamiento contemporáneo en tiempos de pandemias. Editorial Aspo, marzo, 2020; y en La Fiebre, Pensamiento contemporáneo en tiempos de pandemias, Editorial Aspo, abril, 2020. 
"productivo" y la subvaloración de lo "reproductivo"; la necesidad de visibilizar el trabajo invisible (el trabajo doméstico) y de defender una ética solidaria de los cuidados (cuerpos, afectos) para contrarrestar la agresividad del modelo neoliberal de competencias individuales y su performatividad del éxito; la politicidad de formas de autogestión comunitaria que cuestionan el discurso meritocrático del modelo neoliberal y su política institucional, etc. El pensamiento feminista ha demostrado cómo lo precario-feminizado apunta al "límite del capital: aquello de lo que no puede prescindir la vida social para continuar", dándoles figuración a los cuerpos concretos de mujeres cuyas labores, infravaloradas por la economía capitalista, sostienen incansablemente las cuarentenas de la pandemia desde la urdimbre más deshilachada de la producción informal. Este señalamiento feminista del reverso oculto del capitalismo que sale hoy a la luz podría convertir a las reflexiones en torno a la pandemia en "el ensayo general de otra organización del trabajo", favoreciendo la creación de mecanismos cooperativos de gestión de lo común que las mujeres han sabido poner en acción. En la formulación de Rita Segato,

El virus podría imponer una perspectiva femenina sobre el mundo: reatar los nudos de la vida comunal con su ley de reciprocidad y ayuda mutua, adentrarse en el "proyecto histórico de los vínculos" con su meta idiosincrática de felicidad y realización, recuperar la politicidad de lo doméstico, domesticar la gestión, hacer que administrar sea equivalente a cuidar y que el cuidado sea su tarea principal. Es a eso que le he llamado en estos días de un "estado materno", como distinto a aquel estado patriarcal, burocrático, distante y colonial del que nuestra historia nos ha acostumbrado a desconfiar ${ }^{10}$.

Comprender el detalle de cómo las ramificaciones de la violencia neoliberal son múltiplemente intervenidas por las tecnologías de la discriminación de género supone aprender del feminismo como depósito crítico de una memoria forjada por experiencias comunitarias y saberes estratégicos.

Siendo tan convincente el aporte del feminismo en el campo de la crítica social contemporánea, resulta algo sorprendente leer a Giorgio Agamben, Slavoj Žižek, Byung-Chul Han, Alain Badiou y otros formular sus diagnósticos y pronósticos

8. Verónica Gago-Luci Cavallero, "Deuda, vivienda y trabajo: una agenda feminista para la pospandemia”. Revista Anfibia y elsaltodiario.com.

9. Op. cit.

10. Rita Segato, "Coronavirus: todos somos mortales. Del significante vacío a la naturaleza abierta de la historia", 19 de abril, 2020, Lobo Suelto. 
epocales sin incorporar sus teorías como referencia principal a la hora de comentar la degradación capitalista o vislumbrar salidas orientadoras a esta crisis civilizatoria. Es más que probable que la pandemia del Coronavirus vaya a suscitar un reordenamiento geopolítico de las relaciones entre Estados que afecte a las soberanías nacionales o postnacionales, pero su saldo más inmediato es el de un implacable deterioro de las condiciones de vida de las identidades y grupos más desfavorecidos que hará recaer nuevamente en las mujeres los mayores costos de este balance necropolítico de despojos y sobreexplotación. La teórica feminista Judith Butler ya nos había advertido de la violencia selectiva y diferencial que usa el régimen capitalista para castigar a las "vidas precarias"11, aquellas vidas consideradas sobrantes por un régimen enteramente volcado a la ganancia económica y al provecho comercial, al espectáculo cultural del consumo como deleite visual. Por lo mismo, el régimen desprecia aquella corporeidad humana que porta como estigma de inferioridad el no cumplir con los índices capitalistas de la optimización de la ganancia o el no verse reflejada en los brillos del éxito individual cifrado en moda, belleza, juventud y sanidad. "Precariedad" es lo que mortifica los cuerpos de la pobreza o la enfermedad que no están incluidos en este ciclo de gratificaciones mercantiles y que echan a perder su ideal de felicidad proyectando en sus brillos las sombras del malestar y del resentimiento. Pero "precariedad" es, también, la intranquilidad de no poder contar con un sostén duradero; el sentirse a la intemperie y deber aguantar las tempestades sin refugio seguro; conocer solo la escasez como regla de vida. Es, además y también, el sentimiento de indefensión que lleva la relación con el mundo a tener que prescindir de todo apoyo firme o duradero. No se puede dar cuenta de las múltiples capas de vulnerabilidad existencial adheridas a la "precariedad" en el lenguaje seco y duro del pragmatismo neoliberal (operatividad, ejecutividad, rendimiento) que solo confía en la tecnocracia de los datos para gobernar la realidad a fuerza de cómputos numéricos y rankings de competencia. Hacen falta lenguajes sensibles a la escasez y la carencia, a la pesadumbre, es decir, lenguajes marcados por una conciencia del daño y la reparación que se encuentran más próximos a las constelaciones de lo femenino en tanto valor rebajado, desacreditado, por aquellos dueños del conocimiento que siguen asociando lo masculino a grandiosas escalas de superioridad universal.

Llama la atención que el derrumbe de certezas y garantías causado por la pandemia en los marcos de interpretación generales de los actuales procesos y sucesos históricos y político-sociales no haya generado en aquellos filósofos, que se apresuraron en intervenir en el debate intelectual, algún tropiezo de categorías o

11. Judith Butler, Marcos de guerra. Las vidas lloradas, Buenos Aires, Paidós, 2010. 
fundamentos que les significara desconfiar de sus propios aparatos de saber. Desde la filosofía o la teoría social, quienes protagonizan —en clave masculina-la escena de figuración intelectual encargada de reflexionar sobre los destinos del capitalismo y la globalización parecen recurrir al mismo dominio de conocimiento y a la misma jerarquía de autoridad de siempre, sin acusar pérdida de control ni fallas de enunciación. Mientras estas hablas siguen ratificando sus pretensiones de totalidad y universalidad del conocimiento con plena legitimación intelectual, se está diseminando en distintos sitios editoriales la escritura de autoras mujeres feministas como una escritura menos interesada en reconfirmar teorías previamente solventadas que en dotar de palabras a lo desintegrado y lo residual mediante una retórica de lo fragmentario. Su búsqueda de texturas afines al desastre de los sentidos causado por la irrupción de la pandemia no se reconoce en la afirmación ni confirmación de verdades trascendentales, sino en las dudas y vacilaciones de una subjetividad en desarme y en las pequeñas narrativas agujereadas por el hundimiento de lo universal-categórico. No es menor el mérito de estas pequeñas narrativas femeninas-feministas de ser capaces de darle voz a lo íntimo, lo doméstico o lo cotidiano sin caer en la trampa de una cierta romantización de la cuarentena como vuelta a la esencia del yo (la "vida interior"), al tomar distancia crítica con el mito humanista del individuo mediante la radicalización del lema feminista que nos enseñó, de una vez para siempre, que "lo personal es político".

\section{DE LA FURIA DESTITUYENTE A LA CREACIÓN PLURAL DE DINÁMICAS CONSTITUYENTES}

Son muchas las incertidumbres que atentan contra las proyecciones de futuro. No sabemos por cuánto tiempo habrá que resignarse a este aislamiento domiciliario y a los mezquinos sustitutos de sociabilidad que nos ofrece (las redes electrónicas, la educación a distancia, el teletrabajo, el consumo de ofertas culturales en módulos recreativos, etc.) ni tampoco cuáles de estos nuevos hábitos de una sociabilidad tele-comunicada perdurarán hacia adelante como entrenamiento definitivo para un futuro de obediencia. Tampoco sabemos a ciencia cierta si, en medio de la adversidad, tendremos la astucia suficiente para "desarrollar nuevas herramientas de desobediencia civil que nos permitan actuar a distancia” (Naomi Klein ${ }^{12}$ ), revirtiendo el uso de aquellas tecnologías que hoy nos separan para transformarlas en medios de interconectividad solidaria que fortalezcan estrategias de oposición

12. 'Naomi Klein y la normalidad: 'Debemos recordar que la normalidad era la crisis', diario La Tercera, Santiago de Chile, 7 de abril, 2020. 
y resistencia. No sabemos aún (no tememos cómo saberlo) cuán hondas son las marcas psíquicas - temores, aprensión, desaliento, impotencia, etc.- que dejará grabadas la epidemia en un organismo social muy perjudicado como para calcular bien la capacidad de aguante de las vidas precarizadas en extremo o el despertar de su renovada potencia de invención política.

La revuelta de octubre de 2019 fue celebrada masivamente en Chile en su carácter de protesta autoconvocada: sin dirigencias conocidas que la lideraran y expresando una manifiesta desconfianza hacia la política institucional, los partidos (incluyendo a la izquierda parlamentaria) y las alianzas entre ellos fueron declaradas impuras y traicioneras de lo que estaría naciendo al fervor de la calle, es decir, la "ingobernabilidad del pueblo" 13 . Las calles se volvieron el escenario de un despliegue insurgente levantado por los cualquiera (trabajadores, jubilados, dueñas de casa, estudiantes, etc.) que tramaron horizontalmente sus quejas y aspiraciones para repolitizar a la ciudadanía no desde las orgánicas políticas sino desde el cotidiano social. Pero las calles de la revuelta de octubre de 2019 se transformaron en algo más que en el soporte de la feliz emergencia de un cuerpo colectivo que reclama con vigor por la falta de justicia social. Se las declaró garantes irreductibles de una espontaneidad rebelde que no se dejaría capturar por ningún aparataje político:

Una calle devocional que utiliza banderas mapuches como apropiación de sujetos lacerados, litúrgica en sus barras bravas, tan nihilista como religiosa en sus abundantes ángeles dantescos, tan marginal como ciudadana, y que ha erigido a un perro ( $\mathrm{iMatapacos}$, un callejero por derecho propio que se resiste a la codificación del poder!) a la intemperie como ícono de la protesta social sin partidos, ni programas. La calle, como partera de la verdad, como sublevación popular, rechaza los juegos de poder (...) y su maquinaria de pactos $^{14}$.

El desborde imaginal de la calle como escenario de la rebelión tuvo al pueblo como fuente redentora de su nueva épica: el "pueblo" como expresión de un "nosotros" unificado por la colectividad de su reclamo en contra de las cadenas de explotación y dominación neoliberales. El "pueblo" insubordinado quedó investido de una positividad absoluta por ser considerado depositario sustancial de una verdad prerevolucionaria (la expresada por el "Chile despertó") que solo espera realizarse. Sin embargo, no existe tal unidad-integridad esencial del pueblo, ya que dicha categoría se basa en una construcción de lo popular cuyo marco y

13. Rodrigo Karmy, “El triunfo popular”, El Desconcierto, 20 de octubre, 2019.

14. Mauro Salazar, "Primera línea y matapacos. La calle inasible", El Desconcierto, 4 de enero, 2020 
bordes están en incesante litigio ${ }^{15}$. El "pueblo" reunido en la Plaza de la Dignidad carece de una identificación homogénea al ser el resultado del ensamblaje de fracciones heterogéneas de subjetividades diversas cuyos trazados de identidad entran en convergencia o divergencia según las posiciones que ocupan sus sujetos en un determinado campo de fuerzas y posiciones. ¿Cómo se moverá la composición de territorios y el diagrama intersubjetivo del "pueblo" bajo la sacudida generada por la pandemia, tomando en cuenta que ya no solo recorren este diagrama vectores utópicos de liberación del deseo que apuntan a un horizonte venidero (cifrado, por ejemplo, en el llamado a la asamblea constituyente), sino urgentes demandas ligadas a necesidades básicas de supervivencia cuyo plazo de satisfacción debe ser inmediato? Ahora que las condiciones de máxima desprotección social en las que se encuentra una población asediada por el hambre y la pobreza exigen la aplicación de políticas públicas de parte del Estado, ¿será prudente reivindicar "la calle innegociable"16 como exterioridad pura que debe vengarse de la institucionalidad política rompiendo, intransigentemente, con todo sistema de gobernabilidad?

El gobierno de Sebastián Piñera está ganando tiempo (un tiempo cuya continuidad le había sido cancelada por el masivo rechazo de la ciudadanía a continuar dominada por el encuadre neoliberal de sus políticas), haciendo que el manejo de la epidemia le permita enlazar oportunistamente con el inicio del proceso electoral de designación de alcaldes y gobernadores que tendrá lugar en el primer semestre de 2021: un proceso llamado a que la derecha recupere poder político para encontrar las formas de incidir con el "Rechazo" en la próxima consulta del plebiscito nacional, impidiendo así la reforma a la Constitución. La salida de la epidemia (llámese "nueva normalidad" o "retorno seguro") se va a ver interferida por contiendas electorales que pondrán nuevamente en primer plano a la política institucional y sus disputas hegemónicas, con el riesgo de que la desintegración de las alianzas opositoras (fracturadas por el conflicto postestallido social que las escindió entre la calle y el Congreso) prive a las fuerzas de izquierda de poder entrar en el debate político de qué entender por "democracia". Frente a este riesgo político, ¿tiene sentido que la izquierda se siga

15. Dice Judith Butler: "Es siempre difícil decir si una sublevación representa todo el pueblo, la esencia del pueblo o una pura reivindicación democrática (...). Por mucho que las sublevaciones pretendan representar la voluntad del pueblo, se encuentra en general otro grupo de gente que rechaza verse representada por la sublevación. Reclamarse de la voluntad popular es un combate permanente, una lucha por la hegemonía. Aunque una sublevación puede parecer expresar la voluntad popular, debemos siempre preguntarnos de cuál versión de la voluntad popular estamos hablando, a quiénes no incluye y por qué". Judith Butler, "Sublevación" en Soulévements, Paris, Gallimard - Jeu de Paume, 2016, pp. 34-36 (La traducción es de la autora).

16. Mauro Salazar, "Destitución, primera línea y potencia plebeya", El Mostrador, 21 de octubre, 2019. 
atrincherando en la dicotomía adentro (poder de Estado) / afuera (autonomía social) en lugar de ir reforzando planos de coexistencia entre organizaciones y partidos, entre la sociedad civil y las instituciones, que diversifiquen el mapa de las alianzas capaces de obstruir la empresa restauradora de la derecha?

Retomar el hilo del debate sobre la asamblea constituyente iniciado en octubre de 2019 para oponerse a la hegemonía neoliberal supone tomar en cuenta que la disminución de todos los recursos de protección social (desempleo masivo, colapso del aparato de salud pública, créditos y endeudamiento, desfinanciación universitaria, etc.) va a obligar a la política a repensar el rol y las funciones del Estado. La izquierda social que apoyó entusiastamente la revuelta de octubre de 2019 festejó la dimensión autonomista (separada del poder político) de la emergencia soberana de un pueblo llamado a autorepresentarse prescindiendo de toda referencia a la figura del Estado y su institucionalidad pública. El peligro (incluso electoral) de que nuevos poderes autoritarios y totalitarios liderados por derechas y ultraderechas vayan a sacar provecho del creciente desamparo social debería llevar a la iqquierda social a querer articularse con algún tipo de izquierda política para incidir con peso en el andamiaje de los poderes instituidos. Quizás la pandemia nos enseñe que no es este el tiempo de abismarse en la negatividad de lo destituyente para revocar cualquier tipo de orden, sino el de crear dinámicas instituyentes que hagan de mediaciones-traducciones entre las fuerzas del desorden que agitan las revueltas y ciertas gramáticas constructivas del poder-hacer que experimenten con la politicidad de las fronteras. Si la izquierda chilena se mantiene imaginariamente cautiva de la "ilusión de octubre"17, la subjetividad en crisis que atraviesa la pandemia no podrá "cumplir su función ética de agente activo de la creación de mundos"18, una función que exige registrar el daño sensible que afectó nuestra valoración de la existencia para luego reparar los vínculos cortados entre cuerpos, subjetividades e instituciones.

17. El peligro de autoexaltación romántico-popular de la revuelta sin una lectura concreta de la situación política ya había sido lúcidamente advertido por algunos antes de la llegada de la epidemia a Chile: "Algunos sectores en las barricadas y en las asambleas, expuestos a los alcances fascinantes de la revuelta, han quedado atrapados en lo que llamaría la "ilusión de octubre", una posición según la cual la masividad y la radicalidad de las jornadas de octubre darían cuenta de una fuerza elevada que permitiría 1) actuar completamente al margen de los tiempos del itinerario constitucional, 2) responder ante el carácter prolongado de la coyuntura con una revuelta permanente, 3) hacer caer al gobierno por el solo hecho de la movilización callejera. Pero hoy debemos leer la realidad aceptando escenarios abiertos y sin las premisas del pasado. Las asambleas no son soviets, la primera línea no es un ejército y la baja aprobación en las encuestas del gobierno y las instituciones no es una crisis de hegemonía". Pablo Abufom, "Los seis meses que transformaron Chile", Rebelión, 23 de febrero, 2020.

18. Suely Rolnik, Esferas de la insurrección. Acciones para descolonizar el inconsciente. Buenos Aires, Tinta Limón, 2019, p. 58. 